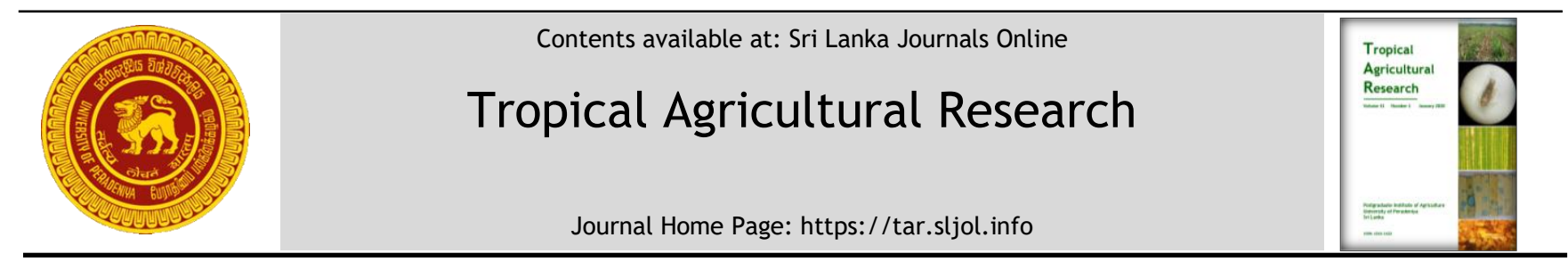

\title{
Role and Capacity of Tea Societies in the Smallholding Sector in Sri Lanka: An Assessment Based on the Perceptions of Extension Officers
}

K.G.J.P. Mahindapala ${ }^{{ }^{*}}$, M.W.A.P. Jayathilaka1 ${ }^{1}$ L.N.A.C. Jayawardane ${ }^{2}$, K.P.P. Kopiyawattage ${ }^{3}$ and M.P.M. De $\mathrm{Mel}^{2}$

${ }_{1}$ Postgraduate Institute of Agriculture, University of Peradeniya, Sri Lanka

${ }^{2}$ Faculty of Agriculture, University of Peradeniya, Sri Lanka

${ }^{3}$ Faculty of Agriculture, Rajarata University of Sri Lanka, Puliyankulama, Sri Lanka

\section{ARTICLE INFO}

\section{Article history:}

Received: 20 June 2019

Accepted: 04 September 2019

Available online: 1 December 2019

\section{Keywords:}

Capacity

Extension

Smallholder

Society

Tea

\section{Citation: \\ Mahindapala, K.G.J.P., Jayathilaka, \\ M.W.A.P., Jayawardane L.N.A.C., \\ Kopiyawattage K.P.P. and De Mel M.P.M. \\ (2020) Role and Capacity of Tea Societies \\ in the Smallholding Sector in Sri Lanka: \\ An Assessment Based on the Perceptions \\ of Extension Officers. Tropical \\ Agricultural Research, 31(1): 43-55.}

DOI: http://doi.org/10.4038/tar.v31i1.8343

Mahindapala, K.G.J.P. iD

https://orcid.org/0000-0002-5466-4123

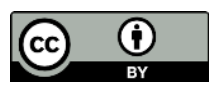

\section{ABSTRACT}

Rural Tea Development Societies (RTS) have been established by the Tea Small Holdings Development Authority (TSHDA) to address the critical issues faced by the tea smallholders. This study attempted to assess the present status and the capacity of the RTS and also identify the attributes that affect their capacity. The perception of Tea Inspectors (TIs), the key entities responsible for extension support for the smallholders, were collected from twelve Focus Group Discussions. The opinions of 65 TIs with over five years of work experiences (who interact with about 575 RTS in seven major tea smallholding area) were analysed by qualitatively.

Results revealed, that the majority of RTS are not performing well due to internal factors such as poor leadership, lack of enthusiasm of members, lack of trustworthiness, status of the members, attitudes of members and also due to external factors such as ruralurban context, government benefits, the role of the extension agent, changes in the external environment, the effect of other organisation and politics. Contribution of the Main Officers, Management Committee and the membership is greater in RTS that are highly active than that of the poorly active RTS. The self-reliance capacity was low in the majority of the RTS and was highly dependent on TIs and the government's assistance. Inbuilt weaknesses in the organisational culture were identified, mainly with respect to attitudes. The majority of RTSs are not goal-oriented. The majority of RTS are not dynamic in organisational performances. Finally, their key extension agents feel that critical intervention is required to overcome the above weaknesses.

*Corresponding author: prasanjithjm@gmail.com 


\section{INTRODUCTION}

Smallholders are the key producers of the Sri Lankan tea industry. The development activities in the tea smallholding sector are handled by Tea Small Holdings Development Authority (TSHDA), and mostly they adopt "Agriculture Knowledge Information System" approach in extension (Obesekara, 2009). Tea Inspectors (TI) are the grassroots level extension workers in the TSHDA. Extension Officer (EO) to the farmer ratio in the sector is around 1: 2700, which makes their task challenging (Anon, 2017). In this background, Government of Sri Lanka took a step to establish the Tea Development Societies, as Farmer Based Organisations (FBO) by a legislative act (No 36 of 1991) in order to facilitate smallholders in the areas of development, marketing, welfare and financing. There are different layers in the Society system- Rural level Tea Society (RTS), district organisation and the national federation. RTS is a ground-level society which is made out of rural tea smallholders. District organisations and national federation are the administrative bodies.

About 1300 societies are operating all over the country under the purview of TIs. A parallel organisation known as Tea Shakthi Fund (TSF) had been established to develop the entrepreneurship of tea smallholders and reinforced with their shares. However, it has collapsed due to various reasons, and subsequently, the shares invested by RTS members were neglected. (Abeythilaka, 2019).

The studies conducted on FBO revealed that they could be used effectively in delivering agricultural technologies and inputs to the rural farmers (Chamala and Shingi, 1997) and also to increase their productivity (Mary,2013).Some authors have identified certain features that should be consisted of a successful farmer organization and they are: target orientation, commitment, positive attitudes, democratic environment, and transparency in activities, membership satisfaction, self-reliance, effective leadership and external support ( Garnevska et al., 2011; Schuppler et al. 2016). Further, Adam Salifu et al. (2012), suggested that if FBOs operate on a business model would be more successful. When considering the local situation, Giragama et al. (1999) observed that the effectiveness of the FBO was greatly influenced by the interaction between the EO and the members. Esham (2012) compared the Japanese Agriculture corporations (JA) model, with local FBOs under the Department of Agrarian Services and suggested to change the structure of the FBO. Further, He suggests networking members, developing the selfsustaining capacity, engage in extension services, farm planning, marketing of farm products, and welfare activities as successful interventions.

Meanwhile, the tea smallholding sector has not been performing well since the recent past. TSHDA has never been able to achieve the minimum replanting rate of $2 \%$ to be maintained even after the establishment of the society (Anon 2005-2017). As shown in table 1 , there has not been seen a significant improvement in the key indicators over the past 15 year's period. The development role expected through the societies appears to have failed to realise. On the other hand, the capacity and present status of the RTSs have not been assessed. The objective of the study was to assess the capacity of the RTS and identify the attributes that affect the capacity.

Table 1: Performance indicators in the smallholding sector in 2007 and 2017

\begin{tabular}{lccccc}
\hline Year & $\begin{array}{c}\text { Productivity } \\
\text { (kg/ha/year) }\end{array}$ & $\begin{array}{c}\text { Production } \\
(\mathrm{kg})\end{array}$ & $\begin{array}{c}\text { Indicator } \\
\text { Replanting } \\
\text { (ha) }\end{array}$ & $\begin{array}{c}\text { Infilling } \\
\text { (ha) }\end{array}$ & $\begin{array}{c}\text { Extent } \\
\text { (ha) }\end{array}$ \\
\hline 2007 & 2039 & 224.8 & 1024 & 41.28 & 119,492 \\
\hline 2017 & 1995 & 232.4 & 748 & 45.13 & 116,492 \\
\hline
\end{tabular}

Source: Annual reports TSHDA 2007 and 2017 


\section{MATERIALS AND METHODS \\ Research design}

This study has focused on the role of RTS through the experiences of TIs who are closely associated with RTS. Thus research comes under the phenomenological science. This study is based on the TIs perception on RTS under the present context, and it is an Interpretative Phenomenological Approach, (Smith and Osborn, 2003). To minimise the possible bias towards the phenomenon being studied, RTS members were excluded in the data collection.

\section{Data collection}

Research participants (TI) belonged to different sub-regions of the various districts, each participant responsible for a specific geographical area known as TI range. TIs are the closest officials to the RTS. Under each range, there can be several RTS ( $>3$ ) based on the size and population density of the range. (Source: TSHDA reports). Data were collected through the Focus Group Discussion (FGDs) using unstructured interview guide (Metron et al.,1956). Twelve FGDs were conducted covering major smallholding districts, (Galle, Matara, Ratnapura, Kegalle, Kalutara, Uva and Kandy) and the participants were selected for the FGDs purely on purposive manner based on the working experience (with a minimum of 5 years of experience) under the guidance of the Regional Managers of the TSHDA. The total number of respondents was 65 , which is nearly $50 \%$ of the total TIs who possess a minimum of five years' experience and they provide the services for nearly 575 RTS. The FGDs were held in the local language and were audio-recorded in addition to taking notes by two note-takers. Data collection was concluded through theoretical saturation (Bryman, 2012)

\section{Data analysis}

The audio recorded data were transcribed adhering to the method suggested by Colaizzi (1978). Then a set of codes and categories were developed according to the grounded theory approach described by Strauss and Corbin (1990). Based on the literature sited, the organisational capacity of RTS was assessed using 5 dimensions (Table 2). Namely, (i) structure and (ii) functions of the organisation, (iii) how the RTS responds to external institutional support system (environment),(iv) relationship with respective TI, and (v) TIs perceptions of how the RTS should adapt to the future

Table 02: Perception matrix of TIs of the Rural Tea Societies

\begin{tabular}{ll}
\hline Categories & \multicolumn{1}{c}{ Codes } \\
\hline RTructure of & $\begin{array}{l}\text { Nature of RTS, Reasons for activeness, Independency, Financial } \\
\text { management, Composition of the committee. Type of Membership, } \\
\text { Organizational culture, Contribution of medium tea growers, Attitudes } \\
\text { of members, Leadership quality }\end{array}$ \\
\hline $\begin{array}{l}\text { Function of } \\
\text { RTS }\end{array}$ & $\begin{array}{l}\text { Participation of members, Business Involvement, Cooperation with TI, } \\
\text { Goal orientation, Extension, Need identification ability, Communication } \\
\text { of technical messages, Welfare involvement }\end{array}$ \\
\hline $\begin{array}{l}\text { External } \\
\text { Environment }\end{array}$ & $\begin{array}{l}\text { External support, Effect of external organisations Political pressure, } \\
\text { Effect of shadow Organisation }\end{array}$ \\
\hline $\begin{array}{l}\text { TI related } \\
\text { Factors }\end{array}$ & Interaction of TI, Guidance of TI, Facilitation for ICT, \\
\hline $\begin{array}{l}\text { Future of the } \\
\text { RTS }\end{array}$ & $\begin{array}{l}\text { Structural changes, Offering compensation, Offering further, Subsidies, } \\
\text { Developing as business units, Improve physical resources }\end{array}$ \\
\hline
\end{tabular}




\section{RESULTS AND DISCUSSION}

\section{Structural aspects of the Rural Tea Society (RTS)}

This section describes how structural aspects of the RTS perceived by the TIs. Structure of an organisation is a crucial factor which determines its function (Daft,2004).

\section{Nature of the RTS}

About 3-22RTS were under the purview of a Tea Inspector (TI) (Average in the studied area is 9). Based on the opinion of the TIs, there is a variability of activeness of the RTS, even within the range and among the ranges. It was revealed that some Societies in the certain TI ranges are entirely 'silent', where no action has been taken place in the last 3-4 years. The RTSs are classified as A, B and C based on the activeness (measured by involvement in the business, welfare activities, and recordkeeping) by the TSHDA and where A represents the highest level of activeness. According to the TIs, the majority of the RTS is not in the active phase and belong to the ' $\mathrm{B}$ ' and ' $C$ ' category (perform moderate or least activities).Only a few TIs felt that majority of the RTS under their purview act beyond their expectation, and the majority of TIs felt that their RTS are not performing well. It appeared that activeness of RTS greatly depended upon the people in the management committee (MC). In the case of a highly active RTS, usually the Main Officers (MO) and the majority of the MC members and sometimes even ordinary members are deliberately involved in the RTS functions. As explained by one of the respondents "The $\mathrm{C}$ and B grades RTSs hardly get the contribution of MC and mostly one or two MOs work" $\left(\mathrm{P}_{3} \mathrm{D}_{7}\right)$.TIs believe that some RTS are revolved around either President, Secretary or Treasurer who used to be the most influential person at the time, despite the guideline mentioned in the constitution. This is in agreement with the concept of power bases described by French and Raven (1959). Although the MC of these RTS is supposed to meet at regular intervals ( 2 months), and discuss the various issues that affect to the member growers and to make the decision, it was revealed at the discussions that majority of the RTS is not doing so. However, TIs are influencing them to a certain extent, but being the voluntary organisations, TIs are helpless in convincing the $\mathrm{C}$ grade societies. According to the opinion of the respondent, "They concern only about the benefits that they can get and not the responsibilities - only one out of six of my society doing so" $\left(\mathrm{P}_{3} \mathrm{D}_{4}\right)$.

The decision-making process in 'A' grade RTSs are more systematic than that in other societies as MC meeting, and general meetings are conducted at regular intervals. Moreover, it was revealed that $\mathrm{C}$ and some of those $\mathrm{B}$ grade RTS do not have a proper mechanism even to collect the membership fee. It was revealed that some of these good RTS maintain an office building may be with paid staff, generate profits through their operations and engaged in member's welfare (eg. $\left.\mathrm{D}_{8}, \mathrm{D}_{10}\right)$. A respondent mentioned that "Some inactive societies were created in the purpose of acquiring the fertiliser subsidies or any other benefits" $\left(\mathrm{P}_{5} \mathrm{D}_{11}\right)$

The majority of the TIs believed that interruption of TSF has severely affected the tea smallholders, particularly with respect to the RTS activities.

\section{Reasons for activeness}

In the present study, it was attempted to find out various reasons which are responsible for the variability in the activeness.

Role of leadership is the most crucial variable highlighted in almost all the discussions. The participants had a strong opinion regarding the relationship with the activeness of RTS and good leadership qualities of the MOs. Talented leaders could guide the MC and take the RTS to success while giving benefits to members. The role of leadership in organization is instrumental and it was described by many authors (Judge, et al. 2002). $\mathrm{P}_{3} \mathrm{D}_{1}$ mentioned that "In that program, Effective leaders quickly 
accomplish the basic requirement and distribute the Glyphosate timely to the members" $\left(\mathrm{P}_{3} \mathrm{D}_{1}\right)$.There were many conflicts among the members of the $\mathrm{MC}$ with poor leadership quality, and that affects the outcome of RTS. The one who appointed as MO should able to influence the others in the MC to get their support, and that ensures the participation of the other members for the various activities.

"One of my societies had been performing well under good leadership. However, with the time people with the skills have been appointed, and RTS has become inactive, leaf dealing activity got affected and ran at a loss." $\left(\mathrm{P}_{2} \mathrm{D}_{4}\right)$.

Moreover, they expressed that members have a passion for appointing elite people to the leadership. Older people with less physical fitness are also appointed and TI finding difficulties to work with them. The commitment of the committee members also matters to a great extent to the journey of RTS. It has not been raised the issues related to gender in management with respect to the activeness of the committee. The majority of the members in certain management committees are comprised of female members. However, there are no differences between female or male dominating RTSs in the particular locality as far as concern the activeness.

The trustworthiness is an essential character of a committee member that raised in the FGD. They required to maintain trust in their actions, and it helps to develop the favourable relationship between the MOs and the members. According to the respondents, a leader should be able to share the benefits with followers. It is not only sufficient to accumulate the profit in the accounts, but also needs to share with the members, which encourage them into further activities. As express by one respondent, "Some RTS generate profits. But they do not take measures to share the profit. This type of things also causes membership to stepdown" $\left(\mathrm{P}_{8} \mathrm{D}_{8}\right)$.

MOs, MC, Membership, Ex MC, Patron and TI are the critical stakeholders of RTS. It is necessary to have good interaction with each category. This will provide a kind of framework for self-monitoring and evaluation of the RTS activities and help to lead on a proper track. TIs expressed that sometimes certain RTS are established for specific reasons, mainly to acquire particular benefits. There is no rationality to the existence of the society after achieving those benefits; thus, the activity of such RTS gradually tend to slow down. All the RTS are highly concerned about the benefits and subsidies that are given by the government. "Those who have left the society will be rejoined when the government introduces a beneficiary program," said $\left(\mathrm{P}_{4} \mathrm{D}_{6}\right)$.In the majority of the discussion, TIs explained how rural environment favours the proper functioning of the RTS. The RTSs located in rural areas function better than the RTS close to urban or semi-urban areas. According to respondents' opinion, specific socio-environmental factors such as poor infrastructure, lack of facilities which are common in the rural areas would have motivated members to solve the problems using collective approaches. In addition, another geographical factor that affects the activeness of RTS is the dispersion of smallholders in a particular location. When smallholders are far apart from each other, disperse within the domain of the RTS, people have to travel a long distance to attend RTS activities. As mentioned by respondents "This area with dispersed settlements. Some of them have to travel more than $20 \mathrm{~km}$ to attend a society meeting, and we see poor attendance in most of the meeting" $\left(\mathrm{P}_{4} / \mathrm{P}_{1} \mathrm{D}_{7}\right)$

The status of the tea grower - whether they are full-time tea grower or part-time tea growers is another factor which closely related to the rural factor. The majority of the TIs argued that full-time farmers fully engaged 
in tea cultivation related things and their preparedness in RTS activities is high as it is a part and partial of their business. In contrast with the part-time tea growers, they may be an employer, self-employed, or other farmer and have to engage in many activities. $\left[\mathrm{P}_{4}\right.$ mentioned that "the majority of the farmers in "KK" area are full-time farmers and the RTS has 650members, and they are highly collaborative with the Society activities" at the discussion 6]. Furthermore, the rural factor has some close association with the part-time tea-growing scenario as they have fewer opportunities compared with semi-urban farmers.

Role of the TI is instrumental in the existence of RTS. However, some TIs argued that present variability of activeness has no relationship with $\mathrm{TI}$ as all the TIs in the country, equally maintain the excellent interaction with RTS, and thus it cannot be a fact for the present status. However, some of them argued that if they are not interfering, some of the societies would have become 'silent'. Based on the overall knowledge on RTS, Authors fully agreed with the statement. Most of TIs believe that as a result of collapsing of the trust between higher authority and the RTSs due to recession of TSF, the RTS members are in a dilemma whether to go with the RTS or withdraw from the RTS, which too has affected their citizenship behaviour in the RTS. Carrying out a good welfare system promotes the group dynamics within the RTS. People were encouraged to attract to the society, which leads to more action of RTS.P ${ }_{1}$ explained it as follows:

"This is the number one society in the country. All the welfare activities of the member farmers are looked after by the society. The donation scheme starts from diagnosis of pregnancy, and continue via delivery, school attendance grade five scholarship, $\mathrm{O} / \mathrm{L}$ qualification and up to the death." (at $\left.\mathrm{D}_{10}\right)$.
In addition to the above factors some isolated reasons came out from individual TIs, such as political influence, poor education level of members, the effect of shadow organisation and some of the external factors and which are described in the later sections.

\section{The dependency of the RTS}

The opinion of the majority of the TIs is RTSs are not independent organisations-they mainly depend on TIs of the particular region. As per the discussions, several reasons can be attributed to their dependency. Firstly, lack of confidence- They are not sure about their strength and always seek help from TIs. Secondly, TIs have power over RTS-TIs are vested certain legitimate power by the act. To acquire various government benefits and subsidies, RTSs members have to approach TIs. Also, lastly, activeness of the society- Some of the Societies are not active, and they survive because of the TIs. It appears that reasonably independent RTSs are quite rare and even not common among the so-called ' $A$ ' grade societies. However, rarely such kind of RTS can exist. ["This particular society mostly independent from the TI. They conducted a meeting on their wish. TI participate as an invitee" $\left.\left(\mathrm{P}_{1} \mathrm{D}_{10}\right)\right]$. On the other hand, although the majority of the TIs are expressed that they want to see these RTS running as independent societies, there are some TIs that they like to keep them under their control by citing some reasons.

\section{Financial management}

As revealed in the FGDs, the majority of the TIs are of the view that accounting procedure of these organisations suffers from lapses such as transparency, incompletion, and mistakes. TIs are not in a position to individually monitor all RTS as some of them have 22 RTS and turnover of some of these RTS are high as they engage in business activities. The most serious issue is that those RTSs failed to adopt a transparent auditing procedure followed by 
the final accounts and that pave the way to miss use of collective funds. This has affected the membership moral and thereby, engagement. Certain RTS who engage in leaf dealing have assets over millions and functioning as close organisations.

\section{Management committee}

As per the constitution, the MC comprises of 3 MOs (President, Secretary, and Treasurer) and eight committee members. Almost all the discussion revealed that there is a trend of appointing the same clique of people to the MC over and again, especially as MOs. Most of these office-bearers are older people who have been holding the post for 10-20 years period. The holding of such a long period of the same person is due to two main reasons: Rest of the committee members do not like to take responsibility and sacrifice their time for the benefits of others; willingness to continue the present person/s. They presume that holding of such type of post is prestigious in the rural settings and that can make use to earn the social capital, and they attempt to acquire the post. Mostly the social elites (people with social status and retired public servants) are selected. The underline assumption would be, such people are capable to manage RTS. ["Mostly, the Principals, Teachers, Post Masters, Bank mangers or any other retired public servants considered. $\left.\left(\mathrm{P}_{3} / \mathrm{P}_{8} \mathrm{D}_{8}\right)\right]$. Nevertheless, in a few places, $\mathrm{TI}$ has expressed that no such factors have been taken into consideration in reorganising the RTS. The other exciting point noticed was those who are holding of the main post in RTS hold the posts in several other voluntary organisations as well. This emphasises leadership deficiency in rural level. On the other hand, the definite question cannot be avoided whether they are efficient to handle that much of work in the same period. It appears that youth are most scarce in the RTS. However, there are some isolated deviations in certain places where some attempts were made to absorb youths into the main leadership by the differently thinking memberships, but even that attempts have also been ended up with mix outcomes (equal proportion of success and failures). TIs also interested in appointing efficient persons to the committee as part of their achievements depend on the nature of the committee.

\section{Nature of the membership}

Both full-time tea growers, as well as part-time tea growers, are in the RTS. As per the general understanding of the TIs broth segment consist of considerable proportions. Existence of these categories depends on various social and environmental factors. The majority of the members are the growers who have less than 5 ac of land and encompasses of middle and senior persons, and youth involvement is at a deficient level. Further, according to the opinion of the majority, youth involvement has been gradually coming down over the last 10 -15 years due to two reasons - shifting of youth from the tea sector, and those young tea growers may have the feeling of themselves not fitting to the present settings in the RTS. This is in agreement with the findings of Lavanya et al. (2018). In fact, as revealed in the FGDs, mostly the growers are not in favour of getting involve their youngsters in the fieldwork. Majority of the members hardly has an interaction with the MC. However, in contrast with this common situation, some pieces of evidence were exposed that, youth are remained in the sector and have some attachment with RTS when a favourable situation arrived. One respondent stated that "One of my societies initiated a program to gather the group of young people by creating a favourable environment that they prefer and succeeded". $\left(\mathrm{P}_{4} \mathrm{D}_{12}\right)$ There are few RTS, where the majority of the members are women. Those women are fulltime tea growers and engaged in RTS activities. The highest percentage of women in membership has also been reflected in the MO/MC. 


\section{Role of medium sector tea growers}

The contribution of the medium sector tea growers (holding size above $5 \mathrm{ac}$ ) towards RTS affairs is low. They are not interested in getting a membership except if it is prerequite to obtain certain benefits. In such cases, they enrol as a member but not take part in any activity. ["They try to pretend they are busy. But the real reason we understood was they felt uncomfortable themselves in the RTS setting feel miss-match" $\left.\left(\mathrm{P}_{2} \mathrm{D}_{1}\right)\right]$.

\section{Organizational culture}

In general, the membership is not much vigilant on MC's actions. Less enthusiasm of members paves the way for MC to do or don't things as they wish and make mistakes. Mostly the critical decisions, as well as the actions, are taken by a few people. ["It is a oneman show in most of the cases" $\left.\left(\mathrm{P}_{6} \mathrm{D}_{11}\right)\right]$.

\section{Attitudes of the membership}

Attitude is one of the main factors that influence poor engagement in RTS affairs. They do not realise what level of potential that they have as a union. ["Better engage in our own activity than attend this' -that is the stance of most of the members". $\left.\left(\mathrm{P}_{2} \mathrm{D}_{2}\right)\right]$. According to the study conducted in Matara district by Bandula et al.,(2016) also found that considerable percentage of membership has less interest towards the RTS affairs. Perhaps, the interest of the members fluctuates over the times. The highest interest was shown in the times that they receive certain benefits. ["Mostly the turnout of the members for the meetings depends on the availability of the benefits in such time" $\left.\left(\mathrm{P}_{3} \mathrm{D}_{1}\right)\right]$. TIs are highly persuaded that attitudes of the society members, including young people, should be changed. This is more justifiable with the following example explained by $\mathrm{P}_{1}$ at $\mathrm{D}_{3}$.

"There was a project that came to increase the replanting rate. The project also gives funds for road development in the rural sector; a condition was RTS has to replant a certain amount. But rather than attempting to achieve their target they try to influence the people and get the funds for the road development. Without doing their part, they seek the benefits".

This attitude problem is seriously affecting RTS development work in relation to business and financial activities. Some MOs engage in frauds and corruptions- use society funds for personal benefits. Thus a shift can be expected in RTSs only if the right persons with correct attitudes are appointed. As described in the previous sections, the contribution of young people, medium growers are low due to some attitudes that they have.

\section{Leadership quality}

Leadership quality matters RTS affairs. According to $\mathrm{P}_{3}$ "People with commitment, knowledge, and capacity to understand the member growers issue will add value to the tea society" (at $\mathrm{D}_{3}$ ). Some RTS leaders who have personal issues with some membership groups would treat differently, and that affects the overall strength of the RTS. Most pathetic issue pointed out by some of the TIs is that when the people with worshipful characters are in the top position, the members of RTS in a dilemma as to 'how they are questioned' when they go wrong which affect society activity. According to $\mathrm{P}_{4}$ "The president of that society is clergy and suspects for miss use of funds. However, no one is going to question"( at $D_{7}$ ).

\section{Functional aspects of the RTS}

The perception of TIs on the operative aspect of the RTS was explored.

\section{Participation of members}

The most of the time participation of members for RTS activities such as general meeting and extension activities organised by the MC is poor, under normal circumstances, the level of participation does not exceed the $50 \%$ of the 
total membership, and mostly the same individuals are presenting for every event. It appears that those enthusiastic minority groups have a moral relationship with the RTS and perceived these events as their essential responsibilities. All the smallholders in the village are not the members of RTS, yet when monitory benefits reached those none members enrol in the RTS.

\section{Involvement in business}

It was exposed that very few numbers of RTS are engaged in business activities. Most of these business activities are confined to the leaf dealing, Inputs distribution and running shops. In history, there were many RTSs engaged in leaf dealing, but because of some corruption, frauds and poor management, they were shutdown. Majority of the business running RTS is in Uva. The successful business generates the income and which mostly invested in the welfare activities, and that helps to tie the members to the society.

\section{Cooperation for TIs work.}

All TIs are unanimously accepted that they need the support of RTS in their extension and development activities as they cannot reach many no. of smallholders. ["Actually we feel that we get good strength because of the society" $\left.\left(\mathrm{P}_{4} \mathrm{D}_{1}\right)\right]$. In fact, it is one of the primary objectives of establishing RTS. Moreover, TIs are of the opinion that all RTSs do not equally support as they expected. RTS support depends on the nature of the work. Mostly they give support in organising extension events. However, if they are assigned more extensive work they use to avoid. TIs were given a target and to achieve them they need support from societies. It should better be understood that it is a situation that TIs are making use the RTS to achieve their targets than society voluntarily provides it.

\section{Goal orientation.}

Except for very few RTS, majority- as organisations have not set a goal or a target to be achieved after the specific period and no activity plan has developed. Since TI has some targets, they have prepared an activity plan and fit into the RTS. However, in the point of view of RTS, that does not match with the organisational development perspective of the RTS but match with the individual development of the tea growers.

\section{Initiation of extension programs based on their own needs}

Tea societies engage in the extension activities which are organised by TIs. However, enthusiasm in organising such activities based on their own interest was very poor. There are few active (A category) RTS effectively utilise the TIs to fulfil their knowledge gap.["I have only one active society under my purview, and they come up with some topics and request me to conduct training program" $\left.\left(\mathrm{P}_{5} \mathrm{D}_{4}\right)\right]$. Mostly due to lack of enthusiasm, they do not engage in this voluntary behaviour and sometimes due to a poor resource-based as well.

\section{Need identification}

Need identification is an essential component in the extension. If the RTS facilitates the existing mechanism, the MC should take appropriate action to identify the needs of members and convey to the TIs. However, the TIs are of the opinion that, MCs do not have a proper mechanism to identify the growers' needs. However, some MC, identify the specific felt needs, such as some problems, occurred in the field that has a severe impact. ["The ant problem occurred in my area was identified by the respective $\mathrm{MC}$ and reported $\mathrm{me}$ " $\left.\left(\mathrm{P}_{1} \mathrm{D}_{4}\right)\right] \mathrm{In}$ addition to that, the MC of an active RTS can grasp the serious knowledge gaps. However, the majority of the MC does not bring their issues to the TIs.

\section{Reaching a message to the bottom}

TIs perceptions were evaluated regarding the diffusion of an extension message to the grassroots level when it is dispatched to the 
MC. When they are received, the messages are treated in multiple manners, such as transmitted to the entire membership, fraction of the membership, with efficient manner, slowly, accurately or with some distortion. This depends on various factors such as activeness of RTS, dispersion of the membership, size of the RTS, the relevance of the message RTS, number of times stimulated, personal characteristics and the type of message. ["The message with respect to the glyphosate has spared quickly than a technical message on pruning"]. However, in general, diffusion of the message through the management committee is at a reasonably satisfactory level.

\section{Welfare activities}

The welfare activity is the best indicator to measure the dynamism of a RTS. As described in section 3.1.2., most active RTS engage in the welfare activities, and those RTS which are successfully engaged in business activities utilise the earnings for welfare activities.

\section{External factors that influences the RTS}

How TIs recognised RTSs' response against the external factors/effects was explored.

\section{External support}

It was revealed that all the RTS are highly sensitive to external support in the form of subsidy, financial aids or any form of tangible benefits. It is the most powerful factors that determine RTS activeness. It seems that a latent objective of the establishment of some of the RTS is just to acquire the benefits given by the government.

"They are looking at the only subsidy. The ambition of the creating of some societies is to get the subsidies and resources given by the government" (P1D3).

For most of the society members perceived that the technical inputs have less value than those physical inputs. Even though Tea is commercial cultivation, tea growers are highly addicted to the subsidy and seek subsidy for its every aspect. It is a dependency mentality, developed over the decades through the policies that have been adopted.

\section{Effect of external organisations}

Some of the government organisations are stakeholders of the RTS. Majority of the TIs argued that some of the tasks assigned to the stakeholder organisations are not properly dealt and which too has an impact on the RTS. They argued that smallholders have issues in technologies which has been introduced and that affect the functions of RTS. ["The fertilisers introduced are denied, certain new clones issued are not popularised miss-match between theory and practicality" (P3D2)]. They further argued that machinery is the best solutions to attract the youth, but there is a severe technological gap in this line. They also pointed out that Stakeholder organisation has failed in making effective interventions in following aspects as welltraining of MC members, poor support in leaf dealing and delay in payments and which also has some impact.

\section{Political influence}

Concerning the political influence, there are differences of opinion based on the locality. Some TIs are expressed that political influences are affecting RTS affairs, and some are not. Where there is a political influence, it is on two lines- Those who are in the management committee has deviant political views with the ruling party, try to disturb the development and beneficiary programs. It can happen in vice versa also. The second way is sometimes they try to attempt to capture the power of the RTS.

\section{Effect of the shadow organization}

Sometimes recent development took place in the private tea factories have some influence on RTS, particularly leaf dealing, Input dealing and welfare activities. Because of the 
competition among the tea factories, they offer these services in an attractive manner which cannot afford to the RTS and that affect to RTS to a certain extent.

\section{TI (perceiver) related factors}

\section{Interaction between TI and the RTS.}

RTS helps Tis to achieve the target. Hence, all the TIs believe that the relationship between them and RTS is essential. Therefore, they maintain good rapport with the MOs and the rest of the members of the MC and make use of these interactions in their job settings. To maintain this relationship, they take part in some of their private functions.

\section{Guiding the RTS}

Most of the RTS are guided by the TIs. They guide the RTS on different occasions, such as time of the election of office bearers, organising the extension programs, business activities, financial matters, matters arising in the RTS activities. TIs have a monthly meeting with the MOs of each RTS under his/her purview (known as the Range Development Committee) which is the formal setup that such guidance are given.

\section{Encouraging to use of ICT}

Although the use of ICT, particularly the use of mobile phones to connect the rural people with TIs may be a possible option, which seems to have leased attention of TIs.

\section{Views on future development of RTS}

The various drawbacks with respect to the RTS have been explored. The present study attempted to gather the TIs suggestions as to how those weaknesses can be overcome and their views have been classified as follows.

\section{Restructuring of organisations}

A considerable number of TIs thought that the present framework as a voluntary organisation has to be changed. They argued that these RTS cannot be survived in the current competitive world as an entirely voluntary organisation. However, they are not very precise about the shape of the structure, but mainly they agreed upon 'It should not be in the form of TSF which was failed. However, most of them express that it is necessary to study the structure of a similar organisation operate in a different part of the world, and the best model should be adopted. It is also suggested that mix model of cooperative system and commercial system. The other structural change proposed by some TIs was assigning of a village-level extension worker/social mobilizer to the RTS. Most of them have expressed that it is also necessary to change the mindset of tea smallholders as they have lost their faith. Nevertheless, whatever the changes made in the structure, appointing of the right people to the leadership is a prerequisite.

\section{Offering a compensation}

The majority of the TIs suggested that to offer an allowance for the MOs to recognise and compensate for their time involvement. The underlying assumption is that the activity can be increased through the commitment of the MOs. However, they do not have an exact idea about who should bear the expenditure.

\section{Further subsidies}

Very few TIs have suggested a further subsidy. This is in addition to the subsidy schemes available at present (planting, infilling fertiliser) and it appears that even some TIs has no exception of the way of thinking of smallholder.

\section{Development of physical resources}

At some discussion, it was revealed that resource pool, particularly physical resources, should be developed. These resources include agricultural machinery, buildings, computers, and vehicles. There were two main ideas and one group of the view that the government should facilitate to develop this while others group mentioned that RTS should use their funds. They believe that the involvement of the youth can be increased through this intervention. 


\section{Developing as business entities}

It was articulated that RTS should be developed as business entities. This is also related to the restructuring approach discussed in section 3.6.1 the things like processing, and value addition can also be considered under this.

The status of the RTSs was examined using five dimensions that were highlighted in the literature, based on the TIs perceptions (through their live experiences). The One's perception can be influenced by internal factors of perceivers (TI), the object being perceived (RTS) and Situation (Time or work setting) that the perception is made. Still, in this study opinion of 65 TIs were analysed, and thus there are fewer chances to have contamination effect due to partiality. Therefore it is fair to assume their reflection represent the real situation in the RTS.

\section{CONCLUSION}

The majority of RTS are not performing well due to certain internal and external factors. Internal factors were identified as poor leadership, lack of enthusiasm of members, issues in trustworthiness, status and attitudes of the members, while external factors are rural-urban - context, government assistance, the role of the extension agent, changes in the external environment, the effect of other organisation and politics. Contribution of the MO, MC and is at a superior level in RTS that are highly active than that of the poorly active RTS. The self-reliance status of the RTS is poor as they mainly depend on TIs and highly sensitive to the government aids. Inbuilt weaknesses in the organisational culture were identified, mainly with respect to attitudes. The majority of RTSs are not goal-oriented. In the extension and business perspectives, the majority of RTS are not dynamic in organisational performances. The study suggests the necessity of interventions to address the above weaknesses.

\section{Limitation and direction for future research work}

Only the TIs were used to collect the data on the assumption that they are impartial and none of the RTS members were considered. Therefore, the findings of the study may be subjected to another confirmation study. However, RTS members have personal biases. Hence, a study based on participant observation would be ideal to confirm these findings.

\section{ACKNOWLEDGEMENT}

Authors wish to acknowledge the TIs, RMs, Mr. Kapila Gunarathna, and Mr D. Abeythilaka, ARM Development, of TSHDA for their support in data collection and Ms Nimmi, Damayanthi andthushani for note-taking.

\section{REFERENCES}

Anon, (2005-2017), Annual reports, Tea Smallholding Development Authority

Bandula, G.G., Abeywickrama, L.M., De Zoysa, M. (2016) Tea small holders' perceptions and experience with tea small holdings development societies (TSHDS) in Matara district of Sri Lanka. Tropical Agricultural Research \& Extension 19 (2) pp 222-227

Bryman, A. (2012) Social Research Methods. Oxford University Press, p. 416-428

Chamala, S. and Shingi,P.M.(1997) Establishing and strengthening farmer organizations, a reference manual FAO (Eds. Swanson B.E) Published by Daya Publishing House New Delhi,

Colaizzi, P. (1978) Psychological Research as the Phenomenologists views it. In: Valle RS, King M (Ed) existential phenomenological alternatives for psychology. New York Oxford University Press, p.48-71. 
Daft, R.L., (2004). Organizational theory and design, $8^{\text {th }}$ ed., southwestern college.

Esham,M. (2012) Lesson for Farmer base Organizations (FBO) in Sri Lanka experiences from agriculture cooperative (JA) in Japan, A Journey in harmony sixty years of japan - Sri Lanka Relations (Ed Karunaratne H. D).

French, J.R.P.Jr. and Raven, B., (1959). The bases of social power in D. Cartwright (ed.), University of Michigan, Institute for Social research, pp150-167

Garnevska, E. Liub, G. and Shadbolt N. M. N. (2011) Factors for successful development of farmer cooperatives in Northwest China, International Food and Agribusiness Management Review Volume 14 (4)

Giragama,W.M.G.B., Sanker, S. G. and Samarakoon S.M.A.(1999)Development and strengthening of farmer organizations through farmer convention, Final Evaluation Report, Hector Kobbekaduwa Agrarian and Research and Training Institute.

Judge, T.A., Bono, J.E, Ilies $\mathrm{R}$ and $\mathrm{M} \mathrm{W}$. Gerhardt, Personality and leadership: A qualitative and quantitative Review,Journal of applied psychology, 2002, pp765-80.

Lavanya, N.L, Shyamalie, H.W. De Zoysa, M and Nadheeshani, K.W, (2018), investigation of Labour shortage: Case study in Ratnapura district, Proceedings of research symposium, University of Ruhuna.
Mary, Gyaako Abokyi, 2013, exploring the Farmer Based Organization (FBO) extension approach. A case study of an NGO in Northern Ghana, A Research project Submitted to Van Hall Larenstein University of Applied Sciences Metron R.K Fiske M and Kendall P.I (1956) The Focus interview A manual of problems and Nue York et al., free press

Obeysekara, K.G.B, (2009). Agriculture extension in the tea smallholding sector in Sri Lanka proceedings, agriculture extension conference (ed. Sivayoganadan, C.), SLAEA

Salifu A, Funka R L,Keefe M and Kolavalli S, (2012), Farmer Base Organization in Ghana, working paper 31, International Food Policy Research Institute, K Street, NW, Washington, DC.

Schuppler, L., Mensah, K., Morisse, V. (2016), GIZ Approaches to Strengthening Farmer Based Organisations Inquiry Report Agribusiness and Food Security Working Group (Ed), Moritz Heldmann, Katharina Schlemper, Margret Will

Smith, J.A. \& Osborn, M. (2003) Interpretative phenomenological analysis. In J.A. Smith (Ed.), Qualitative Psychology: A Practical Guide to Research Methods. London: Sage.

Strauss, A and Corbin, J.M (1997) Grounded theory in practice, Thousand Oaks, CA: Sage 